\title{
Terminología del turismo y variación conceptual: análisis del nuevo léxico para modalidades turísticas por motivación
}

\section{Tourism Terminology and Conceptual Variation: Analysis of the New Lexi- con for Tourist Modalities by Motivation}

CARMen Sánchez Manzanares [carmensm@um.es]

Universidad de Murcia, España

\section{RESUMEN}

El objetivo de este artículo es estudiar el nuevo léxico del turismo creado por expertos para denominar modalidades que representan las motivaciones del turista para la elección de un destino. En primer lugar, se establece el conjunto terminológico para el análisis y se clasifica de acuerdo al atractor genérico del destino que motiva la elección. Seguidamente, se analiza la variación conceptual de los términos y se examinan las relaciones semánticas entre ellos. Se concluye que, en el marco de una gestión experiencial del turismo, los términos que representan las diversas motivaciones actualizan la red conceptual de denominaciones conforme se destacan facetas específicas de los atractores para construir la imagen del destino.

\section{Palabras clave}

Turismo; terminología; neologismos; variación conceptual

\begin{abstract}
This paper aims to study the new lexicon of tourism created by experts to name modalities that represent the motivations of the tourist to choose a travel destination. First, the dataset for the analysis is established and classified according to the generic attractor of the destination that motivates the choice. Next, I analyze the conceptual variation of the terms is examined and examine the semantic relationship between them. I conclude that, within the framework of experiential management of tourism, the terms that represent the various motivations update the conceptual network of denominations whenever specific facets of the attractors are highlighted to construct the image of the destination.
\end{abstract}

\section{KEYWORDS}

Tourism; terminology; neologisms; conceptual variation

RECIBIDO 2020-06-20; ACEPTADO 2020-09-14 


\section{Introducción. Objetivos y metodología}

El progreso experimentado por el sector del turismo en el seno de una sociedad liberal, orientada a la satisfacción individual, ha propiciado la creación en el ámbito de una serie de términos relativos a modalidades en los que se focaliza en las motivaciones del turista. Los procesos de gestión y marketing turísticos, tanto institucionales como empresariales, han favorecido la difusión en los medios de estos términos, lo que contribuye a asentar el carácter técnico de la lengua del sector, tantas veces cuestionada como lengua de especialidad. Como señalan Calvi y Mapelli (2011: 10), los neologismos y el uso estable de géneros textuales son factores que han favorecido la inclusión de la lengua del turismo entre las lenguas especializadas. Este léxico categorial que se conforma y el surgimiento de nuevos géneros para la promoción de destinos turísticos sostienen el desarrollo de la lengua para representar el turismo en una perspectiva diferente a la conocida. Esta situación estaría, además, relacionada con la idea de que puede redimensionarse el sector como industria mediante la vigorización de la lengua especializada, lo que justificaría el interés, tanto de los expertos como de los actores de la promoción turística, en la transmisión de la terminología.

El objetivo de esta investigación es doble: 1) determinar el nuevo léxico del turismo que denomina modalidades según la motivación del turista para la elección del destino; 2) analizar la variación conceptual de estos términos del sector, considerando las motivaciones con relación a los atractivos del destino que se seleccionan para su representación. Por ello, nos centramos en un conjunto de términos específicos del turismo, creados por expertos, que, según Calvi (2016: 192-194), forman parte del léxico del turismo propiamente dicho, frente a otro conjunto de unidades que conformarían el léxico de los textos turísticos. Para establecer el conjunto terminológico de análisis recurrimos al BOBNEO, banco de datos del OBNEO (Observatorio de Neología) de la Universitat Pompeu Fabra ${ }^{1}$, cuya metodología consiste en la detección de neologismos en la prensa aplicando como criterio que la unidad léxica no esté recogida ni en el DLE de la Real Academia Española, ni en el VOXUSO. Puesto que el banco recoge datos desde 1989 hasta la actualidad, el período acotado para nuestro estudio es de 30 años, desde el 1 de enero de 1989 hasta el 31 de diciembre de 2019, y, dado que en este período se publican dos ediciones del DLE -la 22. ${ }^{\text {a }}$ en 2001 y la 23. a en 2014-, y se actualiza la versión electrónica -en 2018 y 2019-, y que la edición del VOXUSO es de 2003, veremos que algunas voces que analizaremos son neológicas en alguna etapa, pero no durante todo el período.

Para extraer del banco los neologismos del turismo que nos interesan, aplicamos variables de búsqueda que especificamos más adelante. Una vez obtenidos los datos, clasificamos el léxico denominativo de modalidades de acuerdo a distintos criterios, entre ellos el de la motivación. Clasificamos también el léxico que denomina componentes de la actividad turística (turistas, alojamientos, etc.) y el léxico no denominativo (las formas localizadas en el BOBNEO son, principalmente, adjetivos), pues nos interesa detectar si en estos términos hay representación de la motivación. Tras la clasificación, procederemos al análisis conceptual y la precisión del significado especializado de voces que denominan modalidad por motivación del turista para planificar su

1 En la implementación de datos de este banco colaboran distintos nodos universitarios, agrupados en España en la red NEOROC (Red de neología del español peninsular) y en América Latina en la red Antenas neológicas (Red de Observatorios de Neología del español de América), coordinadas ambas por el OBNEO. 
experiencia y su disfrute del ocio. Para ello, examinamos el contenido diferencial de un término con respecto a otro y las relaciones semánticas entre distintos términos.

Los neologismos del BOBNEO se detectan en diarios de España y América Latina, por lo que es necesario aclarar que el carácter neológico de las unidades terminológicas del turismo se determina con respecto a la lengua de la comunicación general, no con respecto a la lengua especializada. Si revisamos las noticias sobre el turismo en los diarios, podemos inscribirlas, principalmente, en dos bloques: 1) noticias sobre política y gestión turística, como también sobre el impacto del turismo en el lugar: actividades turísticas ligadas al territorio; resultados económicos y previsiones sobre el turismo; actos institucionales para presentación de campañas y otras acciones de marketing, como asistencia a ferias; mercado de productos turísticos; etc.; 2) noticias dedicadas a la descripción de destinos turísticos, destacando sus atractivos y ofreciendo recomendaciones e informaciones de interés sobre el viaje y su planificación. En general, las de este último bloque suelen incluirse en la sección de viajes del diario, mientras que las del primero se publican, bien en la sección de economía del diario, bien en la sección de noticias locales, aunque también pueden aparecer en la sección de nacionales o internacionales cuando tratan aspectos relativos al turismo en el país o en el mundo, especialmente en situaciones de crisis -obsérvese, por ejemplo, las publicadas en el presente sobre la repercusión en el turismo nacional e internacional de la crisis sanitaria por coronavirus-. Con estas noticias estamos, por tanto, ante una comunicación especializada que se desarrolla en el nivel especialista-público general, pero esto no supone sacrificar el significado especializado del léxico empleado en estos textos periodísticos, pues el sector pretende que el usuario identifique productos turísticos y reconozca sus motivaciones en las distintas experiencias que se ofertan. Por tanto, los diarios son medios que facilitan la difusión de estos términos, dando así respuesta a la demanda de información por parte del ciudadano, cada vez más implicado en la planificación de su tiempo de ocio y también más interesado en el turismo como actividad socioeconómica.

No obstante lo dicho, en muchos casos estos neologismos son también neónimos, pues la proposición lexicológica del sector no tarda en llegar al consumidor a través de los medios de comunicación. Esto es, la incidencia en la prensa de la gestión y el marketing, tanto institucionales como empresariales, por el alcance social de un sector vinculado al consumo, facilita una difusión rápida del término recién creado, que, por tanto, puede ser voz neológica en el ámbito de especialidad así como lo es en la comunicación general.

Además de todo lo anterior, queremos hacer notar la rápida identificación por parte del hablante de los términos debido a las implicaciones del llamado turismo 2.0. Somos conscientes de que el acceso a la información turística a través de plataformas digitales por parte del potencial turista, hace disminuir la percepción de novedad; sin embargo, no aplicamos el criterio psicológico de neologicidad, por lo subjetivo del sentimiento de que una voz es de uso reciente, más aún teniendo en cuenta que, entre las varias generaciones de hablantes en este momento histórico, alguna de ellas no ha descubierto el turismo 2.0. En este punto, además, conviene tener en cuenta la distinción de Guerrero Ramos (2016: 64) entre, por un lado, neologismos de emisor y receptor y, por otro lado, neologismos de receptor; puesto que el grado de neologicidad de una misma unidad puede variar según el tipo de receptor del texto, lectores no especialistas pueden identificar como neologismos términos que no lo son para expertos (ya sean estos lectores o autores del texto turístico digital), en cuyo caso se trata de neologismos de receptor y no necesariamente de emisor. 
A ello se suma que, con relación al acceso a la información en las web o portales de Internet, como señala Yus (2010: 68), hay que considerar el entorno cognitivo único de un individuo único: "Estos entornos son tan variados en la calidad y cantidad de información manifiesta durante la navegación por Internet que las interpretaciones resultantes, incluso de un mismo documento, probablemente diferirán sobremanera unas de otras en algunos lectores". En consecuencia, aplicamos únicamente el criterio lexicográfico de neologicidad por ser más operativo y objetivo y porque, además, la orientación de la lexicografía actual a documentar el uso -incluso en obras normativas-, nos hace deducir que las voces no sancionadas mantienen su carácter neológico -ante los neologismos suele adoptarse como criterio de inclusión su extensión en el uso-.

Estas consideraciones nos sirven de preámbulo para acometer el establecimiento de términos del turismo que funcionan como neologismos en la comunicación general. Después, una vez establecido y analizado el conjunto de términos para modalidades por motivación según la metodología expuesta, constataremos que las motivaciones se representan en los términos destacando un atributo específico del destino, el cual se corresponde, como veremos, con una faceta conceptual de alguno de los denominados atractores del destino. En definitiva, mostraremos la diversificación de las motivaciones del turista y cómo esta diversificación encuentra respuesta en las nuevas modalidades en el marco de un contexto cultural distante de aquel en el que se promocionó el turismo de masas.

\section{Términos del turismo: motivación e imagen del destino turístico}

Los distintos criterios de clasificación del turismo dan como resultado distintas tipologías²; nosotros nos centramos en la motivación ${ }^{3}$ como criterio para establecer nuestro corpus de análisis, aunque no es fácil aislarlo de otros, con los que en numerosas ocasiones se entrecruza. Así, veremos que en las denominaciones por motivación, como pueda ser, por ejemplo, agroturismo, se entrelaza la motivación de la experiencia en el medio rural con otro criterio como es el modelo de desarrollo (impacto sobre el entorno), pues el término integra la noción de la preservación del espacio rural. En un trabajo anterior (Sánchez Manzanares 2020), en el que abordamos la elaboración terminológica con relación a la sostenibilidad del turismo (turismo ecológico, turismo sostenible $e^{4}$, turismo verde, turismo alternativo, etc.), hemos deslindado la categorización de la motivación de esta otra categorización en la que puede subsumirse.

En el modelo FAS (Factores, Atractores y Sistemas de soporte), desarrollado en el seno de un proyecto en el que colabora la Organización Mundial del Turismo y cuya concepción data de $2002^{5}$, se identifican en la estructura de un destino tres dimensiones, que se concretan como sigue (Osorio 2005: 101-104):

2 El turismo puede ser clasificado según diferentes criterios; Orte Bermúdez (en Calvi 2001) señala, por ejemplo, los siguientes: procedencia del turista; edad; medio de acceso; movilidad del turista; motivaciones; tipología del núcleo receptor; repercusiones económicas; tiempo de permanencia; forma de viajar.

3 Para las condiciones sociales de las motivaciones, cf. el trabajo de Álvarez-Sousa (1994).

4 Sanmartín (2016a: 181) advierte que la diferencia entre ecológico y sostenible/sustentable radica en que en el primero no hay contenido referido a daño al medio ambiente, mientras que el uso de cualquiera de las variantes sostenible/ sustentable implica un impacto o daño mínimo.

5 El objetivo de este proyecto es evaluar acciones y estrategias de empresas e instituciones en el sector turístico para comprender la estructura de los destinos (Fayos-Solà, Muñoz y Fuentes 2011: 37). 
1) Factores o Recursos:

- Recursos naturales: agua; tierra; clima.

- Recursos humanos: capital humano; tradiciones culturales, mitos, leyendas; condiciones (estructura y coyuntura) laborales del entorno de trabajo.

- Recursos de capital: capital financiero existente; capital físico/infraestructuras (aeropuertos, puertos, carreteras, ferrocarril); potencial para atraer capital foráneo.

2) Atractores:

- Atractores naturales: 1) espacios naturales; 2) playas; 3) actividades itinerantes en la naturaleza.

- Atractores culturales: 1) legado histórico; 2) eventos; 3) estilo de vida de la población local.

- Atractores artificiales: 1) oferta turística de entretenimiento y ocio; 2) organización de eventos; 3) centros comerciales, tiendas, etc.

3) Sistemas de apoyo o soporte: incluyen el conjunto de infraestructuras y procesos pensados para atender al turista: hostelería, incluyendo restauración; transporte; servicios complementarios (salud, seguridad, información turística, etc.).

Los denominados atractores del destino son los que determinan los distintos tipos de turismo que nos ocupan, puesto que, como señalan Fayos-Solà, Muñoz y Fuentes (2011: 41), son las principales motivaciones del turista. Estos atractores quedan procesados en los productos turísticos, de modo que Fayos-Solà (2004: 220) habla directamente de productos turísticos atractores, en los que hay una elaboración de los recursos primarios para motivar el viaje, y entre ellos señala: "experiencia en la naturaleza" (sol y playa, parque natural, aventura, modalidades de deportes), "experiencia cultural" (ciudad, museo, modalidades de eventos y deportes, sites), "actividad económica" (negocio, reunión comercial, modalidades de eventos).

Para comprender los productos turísticos como motivadores del viaje, tenemos que referirnos a la imagen del destino turístico, por su relación con la intención de elección del destino y la satisfacción cuando la visita tiene lugar y por su carácter dinámico, que varía en el espacio y el tiempo (Gallarza, Gil y Calderón 2002: 70-72). En el desarrollo de un proyecto de marketing turístico, se distinguen los siguientes pasos para la construcción de esta imagen:

La construcción de una imagen característica de una localidad define un conjunto de ideas sobre ella; y según Vaz (2002) es una acción para el desarrollo de un proyecto de marketing turístico que debe ser consecuente con los siguientes pasos: Identificación de los atractivos turísticos, evaluación de las condiciones y potenciales mercadológicos, definición de las prioridades; delimitación de los segmentos pertinentes a los atractivos; y definición del público objetivo (Vaz, 2002:95). (Aires y Nicolau 2010: 249).

Por otra parte, Gallarza, Gil y Calderón (2002: 63) elaboran un gráfico con los atributos empleados en estudios de la imagen del destino turístico (IDT); en el mismo, incluyen los que distinguen Echtner y Ritchie (1993), que comprenden el total de los que figuran en estos estudios (excepto el genérico "Actividades varias"). Son estos que enumeramos a continuación: 1) paisaje/entorno; 2) naturaleza; 3) atractivos culturales; 4) vida nocturna y diversión; 5) facilidades de compras; 6) acceso a la información; 7) facilidades deportivas; 8) transportes; 9) alojamiento; 10) gastronomía; 
11) precio/coste; 12) clima; 13) relajación vs masificación; 14) accesibilidad; 15) seguridad; 16) interacción social; 17) hospitalidad residentes; 18) originalidad; 19) calidad del servicio. Como observamos, los atributos de la imagen coinciden con distintos atractores y sistemas de apoyo señalados en el modelo FAS.

Con todo lo anterior, concluimos que para construir la imagen del destino turístico se focaliza tanto en atractores como en sistemas de apoyo. A continuación, comprobaremos que para denominar las modalidades por motivación solo intervienen los atributos específicos de los atractores.

\section{Neologismos del turismo y tipología de términos por modalidades}

La extracción de datos del banco BOBNEO se ha realizado mediante la herramienta de búsqueda introduciendo como variable que el neologismo contenga la forma turismo, pues partimos de que las modalidades de turismo según motivación se denominan recurriendo a las siguientes formas de composición: turismo + [adjetivo], turismo de + [sustantivo], [formante culto-] turismo. Ello lo hemos corroborado realizando una criba en el glosario terminológico Linguaturismo (2014), en el que no hay denominaciones para modalidad que respondan a otro patrón distinto a la inclusión de la base turismo en este tipo de compuestos ${ }^{6}$. Teniendo en cuenta, además, que este glosario tiene como objeto la terminología de la gestión y que se ha elaborado a partir de un corpus textual representativo de la lengua del turismo, se confirma que estamos con estos neologismos ante términos creados por expertos: "se planeó la elaboración de un glosario terminológico relativo a la gestión del turismo que, como se ha visto, constituye el núcleo de creación léxica más especializado del sector" (Calvi 2016: 195).

La variable seleccionada sería suficiente, pues, como señala Calvi, en la lengua del turismo, uno de los núcleos verbales más productivos para la creación de términos es la misma palabra turismo:

Debido a las transformaciones sociales y económicas de la sociedad postindustrial, se han modificado los comportamientos tradicionales, en particular, por lo que se refiere al turismo masificado; se ha difundido la conciencia de las consecuencias negativas del desarrollo indiscriminado; y se han desarrollado formas de turismo más acordes con la sensibilidad y las motivaciones de los nuevos turistas. De ahí que el léxico refleje este dinamismo con una serie abierta de unidades formadas con [turismo + adjetivo] o [turismo + de + sustantivo]. (Calvi 2016: 203).

Así lo hemos constatado en el conjunto de términos para denominar modalidades por motivación extraídos del BOBNEO, pero veremos que turismo, además de núcleo de compuestos binomiales y preposicionales, puede ser también base léxica a la que se adiciona un formante culto. Dicho lo anterior, por las razones que ahora exponemos, manejaremos otras variables. Para asegurarnos de que no han quedado fuera algunos términos del sector, introducimos también las variables turístico y turista, incluso turis ${ }^{\star}$, pues puede darse el caso de que no esté registrada la denominación de la modalidad, pero sí algún aspecto relativo a la misma, el tipo de turista corres-

6 En su análisis de blogs profesionales del corpus Linguaturismo, Carpi (2013: 56) registra turismo entre las diez palabras españolas con mayor número de ocurrencias (en tercera posición, después de reserva y cliente). 
pondiente o alguna acción. Además, por la misma razón, se toman como variables los formantes cultos que aparecen en los compuestos obtenidos (eco-, agro-, etc.), pues pueden usarse para la denominación de otros elementos de la práctica turística, como, por ejemplo, el alojamiento. Por lo mismo, ampliamos la búsqueda para localizar en BOBNEO términos de alojamiento, para lo cual partimos de unidades simples de denominación que extraemos del glosario Linguaturismo para términos de España y del trabajo de Sanmartín (2016b) para términos de América Latina. Por otra parte, dada la asociación del término viaje a la práctica turística, añadimos esta búsqueda, obteniendo [4]: aventura-viaje; ciberviaje; shopping viaje; viaje de incentivos. Por último, para comprobar que no hay denominaciones por préstamo, buscamos: tourism y tourist (inglés); tourisme y touriste (francés) (las formas italianas coinciden con las españolas), así como los equivalentes de viaje: trip (ingl.), voyage y tour (fr.), viaggio (it.); finalmente, añadimos tour (fr.), voz de la que procede tourism (ingl.), que tomamos prestada en español adaptándola. Lo que se persigue con todo ello es confirmar que no se han omitido tipos, pero, además, la existencia de denominaciones de turistas o alojamientos según motivación permite refrendar la modalidad.

Hemos obtenido 68 términos que denominan modalidades de turismo. A continuación los presentamos clasificados en diez tipos: motivación del turista; modelo de desarrollo; medio de desplazamiento; edad; tipo de alojamiento; nivel adquisitivo del turista; procedencia del turista; duración; estacionalidad; sexualidad. De ellos, el que más número de términos agrupa es el de modalidades por motivación, lo que da cuenta de su importancia en la gestión del destino turístico.

1) Motivación [39]': agroturismo; arqueoturismo; astroturismo; aviturismo; bioturismo; enoturismo; espeleoturismo; etnoturismo; geoturismo; micoturismo; narcoturismo; turismo activo; turismo cannábico; turismo corporativo; turismo cultural; turismo cultural y patrimonial; turismo aventura/turismo de aventura; ; turismo de catástrofe; turismo de congresos; turismo de naturaleza; turismo de negocios; turismo de salud; turismo de salud y belleza; turismo de sol y playa; turismo de trasplante; turismo educativo; turismo electoral; turismo enológico; turismo étnico; turismo gastronómico; turismo idiomático; turismo médico; turismo político; turismo rural; turismo sanitario; turismo sexual; turismo suicida; turismo termal; turismo urbano.

2) Modelo de desarrollo (impacto sobre el entorno) [10]: ecoturismo, turismo alternativo; turismo blando; turismo ecológico; turismo experiencial; turismo responsable; turismo sostenible; turismo sustentable; turismo verde; turismo vivencial.

3) Medio de desplazamiento [7]: autocaravanismo; biciturismo; caravaning; cicloturismo; megacrucero; roadtrip/road trip; turismo de cruceros.

4) Edad [2]: turismo de la tercera edad; turismo senior.

7 Se registra también en el BOBNEO torturismo, que hemos dejado fuera de nuestro catálogo por tratarse de un neologismo expresivo que hemos documentado con distintos sentidos en textos que circulan por la red: desde 'turismo que se experimenta como una tortura' (incluso encontramos un juego mediante una falsa segmentación para referirse al sector: sector turismo > sec-torturismo), hasta 'turismo en zonas de tortura', que es el que se registra en BOBNEO.

8 Hemos localizado también en el BOBNEO la unidad aventura-viaje, que no consideramos término para denominar modalidad, pero, por remitir al turismo de aventura, la contabilizaremos entre el total de neologismos extraídos del banco.

9 A propósito de las variantes denominativas turismo sostenible/turismo sustentable, Sanmartín (2016a: 185) muestra que sustentable es más frecuente en páginas de promoción turística en América Latina, mientras que en España se usa sostenible en mayor proporción. 
5) Tipo de alojamiento ${ }^{10}[3]$ : turismo hotelero; turismo residencial ${ }^{11}$; turismo-resort.

6) Nivel adquisitivo [2]: turismo de lujo; turismo de masas.

7) Procedencia del turista [2]: turismo interno; turismo receptivo.

8) Duración de la visita ${ }^{12}[1]$ : mini turismo/ miniturismo.

9) Estacionalidad [1]: turismo vacacional ${ }^{13}$.

10) Sexualidad [1]: turismo gay.

Además de estos términos, encontramos estos otros que no podemos clasificar estrictamente como modalidades [5]: ciberviaje; fam-trip; press trip; shopping viaje y viaje de incentivos.

Con relación a las distintas modalidades, se crean términos para nombrar turistas:

- Relativos a modalidades por motivación [8]: astroturista; aviturista; enoturista; gastroturista; micoturista; narcoturista; paciente-turista; turista sexual.

- Relativos a otros tipos de modalidad [8]: autocaravanista; biciturista; caravanera; caravanista; cicloturista; crucerista; ecoturista; turista de día.

También los siguientes adjetivos:

- Relativos a modalidades por motivación [10]: agroturístico -ca; astroturístico -ca; científco-turístico -ca ${ }^{14}$; deportivo-turístico -cal turístico-deportivo -va ${ }^{15}$; enoturístico -ca; gastroturístico-ca; geoturístico-ca; histórico-turístico; micoturístico-ca; turístico-cultural.

10 Podemos considerar también modalidad de turismo según alojamiento el camping, pero no lo contabilizamos porque en el BOBNEO solo se registra cámping con el sentido 'campamento', no referido a modalidad; camping se sanciona por primera vez en el $D L E$ en la edición de 2001, pero anteriormente se incluyó en el diccionario manual de la RAE de 1983 (consultado en el NTLLE).

11 Se asume que el turista residencial es el que ocupa una vivienda turística residencial, en lugar de un alojamiento hotelero o similar, pero la caracterización de este tipo de vivienda es compleja, como han puesto de manifiesto Huete et al. (2008: 108), pues depende de la subjetividad del residente la identificación de este tipo de vivienda como turística o no.

12 El término escapada con un sentido asociado a la práctica turística ('Abandono temporal de las ocupaciones habituales, generalmente con objeto de divertirse o distraerse') se podría considerar con respecto al criterio 'duración'. No se recoge por estar sancionado este sentido en el diccionario académico desde la edición de 1992 (consultado en el $N T L L E$ ). Actualmente está penetrando su equivalente inglés city break (o, simplemente, break), que no se registra en el BOBNEO.

13 El turismo vacacional se desarrolla en España en verano, Semana Santa y Navidad, por lo que lo consideramos con relación al criterio 'estacionalidad'.

14 En el contexto en el que se detecta este adjetivo, se aplica a expedición: "El año pasado se organizaron por primera vez en España expediciones científico-turísticas para estudiar y observar a estos cetáceos en el golfo de León y el mar de Liguria" (La Vanguardia, 23/07/1994).

15 El término turismo deportivo se recoge en Linguaturismo, donde el contexto con el que se ejemplifica permite observar que es una modalidad desarrollada en un entorno natural: "Empresas relacionadas con el turismo deportivo: caza, pesca, hípica, golf, piscinas, clubes náuticos y aeronáuticos, alquiler de embarcaciones a vela, canoas, lanchas, tablas de windsurf y de surf, nieve y demás actividades deportivas. (Rodríguez-Arana 2007, Código de la Administración Gallega)". No se recoge en el BOBNEO, donde sí se localiza, como vemos, el adjetivo compuesto turístico-deportivo -va, así como la variante deportivo-turístico -ca. 
- Relativo a otras modalidades [11]: cicloturístico -ca; eco-turístico-calecoturístico-ca; inmobiliario-turístico -ca ${ }^{16}$; macroturístico -ca; mototurístico -ca; no-turístico-ca ${ }^{17}$; turístico-comercial; turístico-residencial; turístico-territorial; turístico-urbanístico-ca; snow bird ${ }^{18}$.

Por otro lado, como dijimos, podemos observar la proyección de las modalidades en los neologismos que denominan alojamiento. Relacionados con las de motivación, obtenemos ${ }^{19}$ [11]: casarefugio-albergue; casa-refugio; casa rural; casa de payés; cottage; country hotel20; gastrohotel; granja escuela; hotel-spa ${ }^{21}$; narcoestancia ${ }^{22}$; refugio-hotel. Con relación a las otras modalidades, encontramos [10]: autocaravana; cámping; ecoalbergue; ecoalojamiento; ecolodge $e^{23}$; hotel ecológico; hotel resort; resort; resort-spa; roulotte.

En BOBNEO se recogen denominaciones de otros tipos de alojamiento que no se asocian a ningún tipo de las modalidades vistas [19]: alojamiento boutique; apartotel/apart hotel/apart-hotel/ apartahotel/apartotel2 ; barco-hotel; bed and breakfast/bed\&breakfast; bonhotel; boutique hotel/ hotel boutique/hotel-boutique; bungalow; buque-hotel; casa-albergue; casa-cueva; casa-hospedaje; casa-pensión; condo-hotel/condohotel; hostal boutique; hostal-restaurante/restaurante-hostal; lodge; piso turístico; posada caminera; vivienda-hotel. Igualmente, se encuentran términos relativos a viajeros aparte de las denominaciones de turistas que señalamos [3]: viajero-cliente; viajero-fotógrafo; visitante-viajero.

Con relación a términos que denominan empresas que gestionan turismo por motivación, el único sustantivo que encontramos es [1]: centro enoturístico, referido a bodegas que gestionan visitas turísticas.

Por último, el resto de neologismos del turismo extraídos a partir de todas las variables señaladas, más otras que hemos ido fijando a partir de los datos que van resultando ${ }^{25}$, no aportan datos relevantes a nuestro análisis, pero los presentamos como muestra de la elaboración terminológica en el sector. Son los siguientes:

a) Sustantivos:

- Empresas [3]: operador hotelero; operador turístico; tour operador.

- Medio de desplazamiento [3]: tren turístico; crucero boutique; minicrucero.

16 Se documenta en el BOBNEO en este contexto: “ ¿Volverán a recurrir al modelo inmobiliario-turístico que se acaba de abandonar?" (La Vanguardia, 01/02/2009).

17 Se emplea referido a turismo en lugares no turísticos.

18 En el diccionario electrónico NEOMA, de Sánchez Manzanares et al. (2016), snow bird se define como sigue: 'Que realiza turismo de larga estancia, normalmente durante la estación de invierno'.

19 Hemos incluido aquí los compuestos que incluyen la base refugio, porque, aunque no se incluye en BOBNEO, turismo de montaña es una modalidad de turismo de naturaleza y el refugio un típico alojamiento de esta modalidad.

20 El equivalente español, hotel rural, no se recoge en el BOBNEO.

21 Lo clasificamos aquí por relación al turismo de salud y belleza.

22 Se documenta en BOBNEO en un contexto extraído del diario argentino Página 12: "Fueron silenciados Fausto Alcaraz y Edgar Fernández en zonas rurales donde predominan las narcoestancias, establecimientos que realizan actividades agropecuarias para disfrazar el tráfico de drogas" (17/12/2014).

23 Se registra en BOBNEO el equivalente español ecoalojamiento, pero no la variante alojamiento ecológico.

24 A fecha de hoy, están sancionadas en el DLE estas tres variantes: apartotel, apartahotel, apartotel.

25 Por ejemplo, si tenemos el dato turismo de cruceros, hacemos en BOBNEO la búsqueda crucero. 
- Modelo de desarrollo [5]: burbuja turística; desarrollo turístico; polo turístico; turistificación; sobreturismo.

- Actividades [5]: boat tour; city tour; climbing tour; shopping tour; tubbing tour.

- Servicios [7]: canasta turística; free tour ${ }^{26}$; módulo turístico; tarjeta de turismo; todo incluido; tourist card; visita guiada.

- Otros [15]: check-in; clase turista; desestacionalización; homo-turísticus; neoturismo; puerto home; post-turismo; síndrome turista; turismofobia ${ }^{27}$; turismófobo -ba; turistada; turisteo; turistofobia; turistología; turismática.

b) Adjetivos [3]: turístico-económico -ca; turístico-publicitario-ria; ultraturístico-ca.

c) Verbos [2]: desestacionalizar y turistear ${ }^{28}$.

Recapitulando, hemos localizado 198 términos del turismo en BOBNEO, incluyendo en el recuento las variantes denominativas (del tipo enoturismo y turismo enológico), pero no las variantes ortográficas como, por ejemplo, las que tenemos para apartotel, ni las variantes del tipo boutique hotel/hotel boutique/hotel-boutique. De ellos, 68 neologismos denominan modalidades, siendo los más numerosos los que representan motivación [39], que son los que componen nuestro conjunto terminológico para el análisis. Encontramos, además, vinculados a las modalidades por motivación: denominaciones de turistas [8] y alojamientos [11], y adjetivos [10]; estos neologismos corresponden a las modalidades por motivación registradas y a tres no registradas: turismo científico, turismo de montaña y turismo deportivo.

Como dijimos, el OBNEO aplica el criterio lexicográfico de neologicidad, según el cual una unidad léxica pierde su carácter neológico una vez que ingresa en los diccionarios generales. Por este criterio, y según los repertorios lexicográficos de exclusión de los que se sirve, dos voces de las treinta y nueve que analizaremos son neológicas solo durante alguna etapa del período acotado para nuestro estudio: agroturismo, por estar registrada en el VOXUSO, de 1989 a 2003; y turismo rural, que se incluye en la edición de 2014 del DLE, de 1989 a 2014. Se trata, además, de las dos denominaciones que se registran en fechas más tempranas en el BOBNEO: agroturismo en 1990 y turismo rural en 1995. El resto son neologismos en toda etapa y en el presente, puesto que los datos neológicos que no se registran en el DLE de 2014, tampoco aparecen en la edición electrónica actualizada. De hecho, de las 243 palabras nuevas que registra el DLE 2.3. en 2019, solamente pertenecen al ámbito del turismo apartahotel y aparthotel, variantes de apartotel, registrada por vez primera en la edición de 2001.

26 No se recoge en BOBNEO el equivalente español: visita gratuita.

27 Sanmartín (2019: 68-69) ha mostrado cómo en turismofobia hay una carga ideológica mayor que en turistificación, por ser más transparente el primer término, en el que se identifica fácilmente el sentido 'aversión' a partir del formante -fobia, mientras que es más difícil interpretar el segundo, que alude a la masificación y a otros factores del turismo que producen efectos negativos.

28 El Diccionario del español actual (1999), de Seco et al., registra turistear ('Hacer turismo') con la marca raro. Sanmartín (2019: 69) indica que su uso con el sentido 'viajar por placer, visitando lugares en poco tiempo' se restringe a zonas del español de América. 


\section{Variación conceptual y relaciones semánticas entre términos}

En este apartado analizamos cómo se representan las motivaciones en los términos de acuerdo a la faceta conceptual del atractor del destino que se hace prominente. Para ello, es necesario analizar el contenido diferencial de un término con respecto a otro con el que mantiene una relación de sinonimia (parcial o total) o de hiponimia, pues permite clarificar la perspectiva con la que se representa la motivación; así, en el caso de la sinonimia parcial, al determinar la faceta del concepto que se destaca en cada término ${ }^{29}$, esclarecemos su necesidad denominativa en el marco de la red de la que forma parte.

Anteriormente indicamos que la elaboración del producto turístico se muestra inseparable de la imagen del destino, que se construye en cada uno de los 39 términos detectados mediante la representación de atributos, si bien puede categorizarse un atributo genérico o uno específico. Lo primero que comprobamos es que en los 39 se representan atractores, que son, por tanto, los motivadores del viaje. Antes de continuar, queremos precisar que bajo turismo de naturaleza y turismo cultural se podrían englobar la mayoría de términos que representan, respectivamente, concretos atractores naturales o culturales. Un hiperónimo como turismo de naturaleza activa distintas redes conceptuales dependiendo de la confluencia de la actividad del turismo con otros dominios, lo que genera términos que descienden de ramas conceptuales distintas; de este modo, en la intersección de turismo de naturaleza con deporte encontramos hipónimos como turismo activo, mientras que si lo turístico interseca con campos de las ciencias naturales, obtenemos otros como aviturismo, espeleoturismo, etc. Del mismo modo sucede con el hiperónimo turismo cultural, donde podría situarse, por ejemplo, turismo étnico, que compete al turismo y a la etnología, mientras que en otras ramas hallamos otras unidades, por ejemplo, turismo gastronómico, que pertenece tanto al dominio del turismo como al de la gastronomía. En cuanto a los productos vinculados a atractores artificiales, podría considerarse que corresponden a modalidades con una motivación comercial -muchas veces por circunstancias legales-, pero no es claro que el turismo de negocios englobe los distintos tipos que puedan encontrarse, a excepción del turismo corporativo y el turismo de congresos, que tradicionalmente se han señalado como subtipos.

Santana (2003: 32-34) señala que, a finales de los ochenta y principios de los noventa, comienza la oferta de nuevas formas de turismo diferenciadas del turismo de masas, con productos enmarcados en dos paquetes vinculados: naturaleza y cultura (destaca entre esos productos los denominados ecoturismo, turismo étnico, turismo rural y turismo cultural). En la actualidad, se acrecienta considerablemente el número de estos productos turísticos que aúnan atractores naturales y culturales. No obstante, consideramos que, si bien la extraordinaria reconceptualización del turismo determina que confluyan en lo representado por los términos tanto atributos naturales como culturales, incluso artificiales, se hace prominente un tipo de atractor. Por ello, propondremos una clasificación de modalidades por motivación estableciendo como criterio el tipo de atractor al que conciernen: natural, cultural o artificial. Esta clasificación no implica que no valoremos en el concepto representado por cada término las concretas facetas de distintos tipos atractores que pueden actualizarse. Por el contrario, en el análisis que realizamos de los términos valoramos

29 Para Cabré (2008: 32), en la sinonimia parcial, puesto que hay variación tanto de la denominación como del contenido, cada sinónimo actualiza una faceta del concepto, esto es, actualiza el concepto de manera parcial. 
su contenido especializado observando las distintas categorizaciones de un mismo atributo. Teniendo en cuenta esta variedad conceptual, examinaremos las relaciones semánticas entre los términos. Por consiguiente, la red conceptual de denominaciones para modalidades se actualiza a medida que se van estableciendo los atributos destacados. Así, aunque situemos etnoturismo entre los atractores culturales, porque, en nuestra opinión, se prioriza el atractivo antropológico de una cultura "exótica", valoramos que incluye también atributos naturales por hacerse presentes los valores ecológicos del entorno. Igualmente, el turismo rural, que situamos entre los atractores naturales, tiene un componente cultural, referido a la vida de los lugareños en el medio rural. Finalmente, en una modalidad como es turismo de salud pueden destacarse tanto atributos artificiales si consideramos que engloba un subtipo como es el turismo de trasplante, como atributos naturales en el caso de turismo termal.

Por otro lado, las modalidades no se definen únicamente con relación a determinados atributos, sino por contraposición al turismo convencional. Así, el etnoturismo (o turismo étnico) se observa hoy día como forma de turismo alternativo -contrapuesto al turismo de masas-, en la medida que se hace prevalente el valor de sostenibilidad del entorno, ligado a la ecología tanto como a la interculturalidad. Como hemos mostrado en un trabajo anterior, se ha modificado parcialmente la ideología por la que se asociaba la explotación turística de un lugar a un beneficio económico, de manera que hoy solo se asume que hay beneficio cuando el desarrollo del turismo es sostenible (Sánchez Manzanares 2020: 16). Esto es, el respeto al medio ambiente y al entorno y la solidaridad con la comunidad que habita un lugar, han conducido a la reconceptualización de los términos que analizamos. Por esta razón, se han extendido términos como turismo ecológico o turismo verde, en los que el foco se coloca en la preservación del medio ambiente más que en la naturaleza como atractor/motivador del viaje.

Por último, como ha señalado Varo (2017: 205), los participantes en un acto comunicativo establecen contrastes entre unidades léxicas consideradas cuasisinónimas en el sistema. Si se interpretan como equivalentes unidades que conviven en el uso, puede suceder que una de ellas se consolide y finalmente desplace a las otras, o bien que se imponga una diferenciación semántica en el caso de que se actualice la red de relaciones entre términos por reconceptualización de los mismos. También puede suceder que al reconceptualizarse un término, se haga equivalente a otro existente; por ejemplo, veremos que turismo de salud y turismo médico/turismo sanitario se emplean en algunos ámbitos como sinónimos, por reconceptualización del término turismo de salud. Por otra parte, es posible que en el propio ámbito de especialidad no se tenga una definición uniforme de una unidad terminológica, lo que conduce a interpretaciones diversas. En ocasiones se debe, precisamente, a que los términos han experimentado un cambio semántico a lo largo del tiempo conforme a la evolución del sector, donde continuamente se ofertan nuevos productos que puedan responder a nuevos retos: tanto a la gradual conciencia colectiva de sostenibilidad y respeto al entorno (cf. Sánchez Manzanares 2020), como a la demanda de experiencias individuales por parte del turista:

En todo caso, los servicios personalizados, el viaje a la carta, la valoración de la autonomía y la independencia, el turismo especializado por funciones y actividades específicas (cultural, gastronómico, deportivo, de salud, etc.), los destinos no convencionales y fuera de temporada, indican un avance cada vez mayor de la individualización y particularización de la actividad turística, limitando el clásico discurso del viaje homogéneo, masivo y repetitivo. (Alonso Benito 2009: 253). 
Dicho lo anterior, organizamos el conjunto de términos de modalidades por motivación atendiendo al atractor en el que se focaliza y seguidamente discutimos esta organización en el análisis que realizamos de los términos, observando que, en algunos casos, confluyen distintos tipos de los atractores señalados en el modelo FAS:

- Atractores naturales [15 términos]: agroturismo; astroturismo; aviturismo; bioturismo; espeleoturismo; geoturismo; micoturismo; turismo activo; turismo aventura/turismo de aventura; turismo de naturaleza; turismo de salud; turismo de salud y belleza; turismo de sol y playa; turismo rural; turismo termal.

- Atractores culturales [13 términos]: arqueoturismo; enoturismo; etnoturismo; turismo cultural; turismo cultural y patrimonial; turismo de catástrofe; turismo educativo; turismo enológico; turismo étnico; turismo gastronómico; turismo idiomático; turismo político; turismo urbano.

- Atractores artificiales [11 términos]: narcoturismo; turismo cannábico; turismo corporativo; turismo de congresos; turismo de negocios; turismo de trasplante; turismo electoral; turismo médico; turismo sanitario; turismo sexual; turismo suicida.

En su estudio para conocer los escenarios de los viajeros europeos en 2015, Valls (2013: 386) señala que uno de los ejes centrales que sustentan estos escenarios es el de la explosión de motivaciones. En cuanto al análisis de las mismas, los resultados de su trabajo muestran que, si bien los turistas escogen destinos en el litoral de forma preferente, la motivación con menor grado de impacto para el turismo en las próximas décadas será sol y playa, alcanzando la salud y el cuidado del cuerpo el mayor grado; las otras motivaciones seguirían el siguiente orden: cultura (creciente interés por el patrimonio y las raíces); eventos (culturales y deportivos) y visita a ciudades y lugares. Después, y siempre por encima de la motivación de sol y playa, estarían, ordenadas de mayor a menor impacto: gastronomía y vino; naturaleza interior; relaciones con familiares y amigos; deporte y aventura; congresos, reuniones e incentivos; estudios; descubrimientos; motivo religioso y peregrinaciones; motivo solidario.

La ordenación anterior es la que seguiremos para abordar, a continuación, las relaciones semánticas entre términos que denominan modalidades por motivación, así como el significado especializado de algunos de ellos.

1) turismo de salud; turismo de salud y belleza; turismo médico o turismo sanitario y turismo termal. Por un lado, turismo de salud puede hacerse equivalente a turismo médico o turismo sanitario, esto es, a un tipo de turismo en el que el objeto es optar a un tratamiento en centros médicos, con lo cual estaríamos en el caso de una sinonimia parcial. Por otro, puede usarse referido a una modalidad en la que, siguiendo a Arias et al. (2012: 78), podrían diferenciarse dos vertientes: turismo de bienestar (termalismo moderno, medicina tradicional, otras terapias) y tratamiento médico (cirugía curativa, cirugía estética, tratamiento dental, rehabilitación, medicina preventiva, tratamiento reproductivo). En este último caso, turismo de salud sería el hiperónimo tanto de turismo termal como de turismo médico/turismo sanitario. Coincidiendo con lo que acabamos de señalar, en el informe de 2013 de AUREN sobre turismo de salud en España, elaborado para la Escuela de 
Organización Industrial (EOI) del anterior Ministerio de Industria, Energía y Turismo, también se identifican dos subsegmentos en el turismo de salud: turismo de bienestar y turismo médico ${ }^{30}$.

Un turista de salud sería alguien que viaja en busca de un servicio club de salud o spa para reducir el estrés, de tratamientos termales o de procedimientos más complejos en un hospital. Desde la perspectiva del sector turismo, el turismo de salud implica la promoción consciente de que viajar a determinado lugar se considera beneficiosa para la salud debido a un clima particular, a los recursos naturales o a los servicios de salud que se proveen en dicho lugar (Goodrich, 1994). Carrera and Bridges (2006, p.447), por ejemplo, definen el turismo de salud como el viaje organizado fuera del entorno habitual del usuario, para el mantenimiento, mejora o recuperación de su bienestar individual físico y mental. (AUREN 2013: 11).

Se plantea, entonces, la cuestión de por qué hemos agrupado en bloques distintos turismo de salud y turismo médico. La razón por la que catalogamos, por una parte, el turismo de salud y el turismo de salud y belleza en la clase motivada por atractores naturales tiene que ver con la inclusión de atributos beneficiosos para la salud, como el clima, las aguas termales, etc., mientras que el turismo médico está motivado por la capacidad de gestión pública y privada de servicios de salud en un lugar, y no tanto por la existencia de recursos naturales, por lo que lo situamos entre los atractores artificiales.

También se ha relacionado el turismo de salud y bienestar con el turismo ecológico; así, Estornell (2016: 113) observa que "es frecuente hallar referencias de turismo ecológico en información sobre turismo activo o de salud y bienestar, y viceversa", lo cual explica porque en ambas modalidades se destacan los contenidos de valoración de la naturaleza y bienestar de la persona. En este punto, se hace necesario señalar la repercusión del ecologismo en el turismo, movimiento que, como señala López Mendoza (2012: 40), surgió para satisfacer necesidades tanto sociales como de salud del ser humano, lo que justifica la interrelación entre turismo de salud y turismo ecológico. En todo caso, todas las relaciones anteriores se explican por la diferente conceptualización de salud, bien con relación a lo saludable desde el punto de vista ecológico, bien con relación a los servicios sanitarios para la preservación de la salud.

Centrándonos ahora en el término turismo termal, vemos su evolución conceptual, pues pasa de representar exclusivamente a recursos naturales a incluir como contenido el acceso a servicios sanitarios. Así se hace explícito en el estudio de 2018 sobre turismo de salud que realiza el Instituto de Turismo de la Región de Murcia:

La estrategia del Instituto de Turismo de la Región de Murcia (ITREM) para el desarrollo del producto de salud y belleza se centra en el posicionamiento de la Costa Cálida-Región de Murcia a través de un producto integral configurado por balnearios, centros de talasoterapia, spas, clínicas privadas y centros hospitalarios privados. Esta modalidad amplía desde el año 2015 el concepto de turismo de salud y belleza que se había venido promocionando en la Región de Murcia tradicionalmente, y que se centraba en la promoción del segmento wellness (balnearios, talasoterapia y spas). (ITREM 2018: 4).

30 El término turismo médico ha pasado de tener una connotación negativa, por asociarse al fraude de la salud pública que realizan extranjeros, a verse como una oportunidad económica dentro del sector turístico (AUREN 2013: 6). 
En este mismo estudio, se recoge que el intervalo de edad mayoritario de los que consumen el producto balneario es de más de 65 años, mientras que no hay un intervalo predominante para consumo de spas y centros de talasoterapia $(2018: 8)^{31}$. Por tanto, cabría vincular el turismo termal al turismo senior (o turismo de la tercera edad), del mismo modo que el turismo de aventura, que es una forma de turismo activo, se vincularía a un turista joven o de mediana edad. Esto supone que la motivación se interrelaciona con otras variables, en este caso, la edad, lo que podría ser objeto de otro estudio.

2) turismo cultural/turismo cultural y patrimonial y etnoturismo/turismo étnico. En la perspectiva del turismo como actividad económica, el turismo cultural se observa como un producto turístico que contribuye al desarrollo económico regional por cuanto implica "el diseño, la comercialización y la promoción de nuevos productos del patrimonio cultural turístico y las actividades durante la creación de un ambiente seguro y de fácil manejo para los visitantes y las comunidades locales" (Vargas 2013: 36). En esta perspectiva, estaríamos ante un tipo de turismo alternativo, comprometido con el desarrollo local y la comunidad, por tanto, sostenible. Aunque se observe hoy como práctica alternativa al turismo convencional, Santana (2003: 37) hace notar que su impulso tuvo lugar cuando se desarrolló el turismo de masas. Este autor, además, considera que su propósito en la actualidad es la experiencia de la 'cultura' y, por ello, puede incluir actividades que van desde el encuentro con culturas distantes, hasta la observación de monumentos (Santana 2003: 38). Con este sentido, turismo cultural se convierte en hiperónimo de una modalidad como es el turismo étnico o etnoturismo, que se inscribe también entre las modalidades alternativas. Para Santana (2003: 37), el turismo cultural solo se diferencia del turismo étnico en que no cuenta con el rasgo de 'exotismo' y en que puede realizarse como producto complementario en el marco recreacional.

No obstante, sigue existiendo una oferta convencional con respecto a la experiencia cultural, como puede apreciarse en las categorías de recursos del turismo cultural que presenta en un trabajo reciente Prieto Gutiérrez (2015: 103): 1) Patrimonio histórico; 2) Naturaleza; 3) Patrimonio cultural inmaterial; 4) Festivales; 5) Lugares religiosos; 6) Gastronomía local; 7) Cultura moderna.

Lo anterior nos permite plantear dos vertientes en la interpretación del término turismo cultural: tipo de turismo alternativo -por consiguiente, experiencial- donde el atractor es lo cultural en el marco de un turismo sostenible en el que se potencian los valores ecológicos y la interculturalidad; y tipo de turismo convencional donde lo cultural se reduce a la "visita" del patrimonio del destino, esto es, a una actividad propia del turismo recreativo.

3) agroturismo y turismo rural. Para el turismo en el medio rural se han usado otras denominaciones además de turismo rural, tales como turismo ecológico o turismo verde (Loscertales, 1999: 126); incluso, como señala Gil Álvarez (2004: 18), se han empleado como equivalentes ecoturismo, turismo verde, turismo de la naturaleza, turismo rural. Claramente estas relaciones dan muestra de que el atractor en turismo rural es el campo como espacio de lo natural frente a lo urbano. Por

31 Es menos frecuente el empleo del término turismo de talasoterapia, que no forma parte de nuestro catálogo, para denominar una modalidad de salud en la que el atractor son los recursos marinos, no los termales. Se ha definido como sigue: "Ofrece servicios para la cura y tratamiento del cuerpo a base de la utilización del agua del mar. El agua, las algas y las sales son muy importantes en todos sus productos" (Bautista Moya et al. 2016: 5). 
otra parte, en distintos estudios se ha considerado el agroturismo como un subtipo del turismo rural (Guerrero Velasco et al., 2012: 40) caracterizado por las labores agrícolas y ganaderas llevadas a cabo en ese espacio rural. El éxito de estas modalidades puede medirse por el hecho de que turismo rural y agroturismo son los dos únicos términos de nuestro corpus que se han sancionado en el DLE de 2014² (agroturismo, además, se registraba en el VOXUSO de 2003) y, según Cebrián y García (2016: 388) se debe a "la conciencia creciente hacia el medio ambiente y por las preferencias cambiantes de los turistas, en las que adquieren protagonismo el paisaje, los valores y la cultura local, así como las actividades recreativas de ocio y tiempo libre”.

4) arqueoturismo; enoturismo/turismo enológico; turismo de catástrofe; turismo gastronómico; turismo político y turismo urbano. En la mayoría de estas modalidades de turismo cultural se conceptualiza fácilmente la motivación a partir del término que las denomina; así, en arqueoturismo se representa destacando el yacimiento arqueológico como atributo cultural. En otras denominaciones, sin embargo, el contenido es más impreciso. Por ejemplo, turismo político se usa en ocasiones, como se documenta en BOBNEO, con el sentido 'turismo realizado por los políticos cuando ejercen su cargo', pero el sentido que nos compete es el que corresponde a la historia política del lugar como motivación del viaje. Estaríamos, por tanto, ante la denominación de una modalidad de tipo cultural, en la que la motivación que se representa puede explicarse como sigue ${ }^{33}$ :

Viajar evitando los circuitos turísticos convencionales y tratar de llegar a conocer la sociedad real de cada país es una actividad cada vez más practicada. En la actualidad, se visitan otras ciudades y países para aprender in situ la historia reciente del lugar y, especialmente, los hitos relacionados con la historia política del siglo XX. Surge un tipo de turista muy específico que busca lugares con relación política; viajes a la medida para los amantes de lo político. (Longares, Beers\&Politics, 23/10/2017).

Por otro lado, a pesar de su transparencia, no hay una definición unánime de turismo urbano en los estudios de turismo, como puede comprobarse en la revisión que realiza Falcón (2017: 38-43), de la que se extrae, no obstante, su vinculación al turismo cultural y al turismo de negocios.

En cuanto al turismo de catástrofe, en el diario uruguayo El Observador, se daba cuenta recientemente $^{34}$ del auge mundial de esta tendencia a visitar destinos maltratados por catástrofes o siniestros, lo que algunos valoran como un turismo solidario -en la medida que el turismo es fuente de riqueza-, mientras que otros lo consideran un turismo "de morbo". Esta inquietante forma de turismo cultural se incluye en el denominado dark tourism (esp. turismo oscuro/turismo negro), que, como señalan Chierichetti et al. (2019: 9), tuvo gran resonancia en el ámbito académico a partir de la publicación en 2000 de Dark Tourism: The Attraction of Death and Disaster, de Lennon y Foley.

32 En el DLE, agroturismo se define como sigue: 'Turismo rural, especialmente el que incluye actividades agrícolas y ganaderas'.

33 La cita la extraemos de un artículo de la web de comunicación política Beers\&Politics, al que puede accederse en el siguiente enlace: <https://beersandpolitics.com/turismo-politico-valencia>

34 En la sección de Economía y Empresas del diario se publica la noticia, accesible en el enlace: <https://www. elobservador.com.uy/nota/chernobyl-la-serie-que-impulsa-la-tendencia-del-turismo-de-catastrofes-20197810505> (El Observador, 08/07/2019). 
Por último, el enoturismo o turismo enológico, aunque a veces se subsume en la categoría gastronómica, en la actualidad representa un turismo diferenciado, centrado en rutas enológicas ${ }^{35}$.

5) turismo activo y turismo de aventura. Rivera (2010: 256-257) hace una aproximación al turismo activo de naturaleza como una forma de turismo rural, para después caracterizarlo como un tipo de turismo alternativo y relacionarlo tanto con el turismo deportivo como con el turismo aventurero, señalando sus orígenes en el siglo XIX en los clubes alpinos de montaña ${ }^{36}$. La diferencia que encuentra este autor entre turismo activo y turismo de aventura es que en este último las actividades se desarrollan "en medios naturales más singulares, lejanos y recónditos, de peligro que los caracteriza y que se asocian a la propia promoción de la individualidad" (2010: 265). Por consiguiente, el turismo de aventura se engloba en el turismo activo, situándose el foco más en el riesgo del lugar exótico que se visita que en las actividades físico-deportivas, que son las que se focalizan en turismo activo:

En definitiva, el turismo de aventura hace referencia a viajes a destinos lejanos o exóticos, poco desarrollados, donde se buscan experiencias intensas a las que no se tiene acceso en la vida cotidiana y que conlleva la práctica de algunas actividades físico-deportivas, con cierto riesgo en ocasiones, pero sin ser éstas la verdadera motivación del viaje. (Moral et al. 2013: 335).

En este turismo de aventura se busca la autenticidad del destino (Moral et al. 2013: 336), valor que es común, según Salazar (2006: 104) a cualquier forma de turismo alternativo.

6) turismo educativo y turismo idiomático. Estamos ante subtipos del turismo cultural en los que el foco atractor no son los recursos culturales, sino que la motivación es el aprendizaje, en ocasiones en el marco de actividades extraacadémicas programadas por centros educativos. Según Talón y Figueroa, el turismo educativo es "aquella modalidad del turismo cultural en la que la motivación principal del turista es la de aprender. En relación con otras tipologías de turismo se podrían incluir las granjas-escuela y los centros de interpretación” (2009: 158).

7) bioturismo y geoturismo. Por la comprensión por parte del hablante del formante bio-, que nos remite a lo biológico, el término bioturismo es, aparentemente transparente, pero se hace necesario precisar su contenido: representa una modalidad de turismo que focaliza en el atractivo de la biodiversidad de los ecosistemas ${ }^{37}$. Del mismo modo sucede con geoturismo, a priori transparente por el formante geo-, pero que puede interpretarse con relación a lo geológico y, en efecto, este es uno de sus sentidos, o bien, como propone la Fundación National Geographic desde 2009, con relación a las características geográficas del lugar, no exclusivamente geológicas (Carcavilla et al. 2011: 84). En cualquier caso, se conceptualiza un turismo sostenible en el que cobra importancia la dimensión científica del viaje, del mismo modo que sucede en bioturismo. La inestabilidad

35 Así lo definen Talón y Figueroa (2009: 155): “El turismo enológico es una variante del turismo gastronómico cuya motivación principal es la visita a bodegas y la degustación y cata de vinos".

36 El autor indica con respecto a sus orígenes que ya en el siglo XVIII se detecta la demanda de recreación y deporte al aire libre en la Europa occidental.

37 Es una modalidad en la que se apuesta por el desarrollo sostenible del turismo, pues está orientada a la preservación de la biodiversidad (Sánchez Manzanares 2020: 13). 
semántica es propia de los neologismos y, por lo que respecta a geoturismo, la fuerza del ámbito anglosajón puede ahondar en la indefinición, lo cual se evitaría si se usara la variante turismo geológico (no registrada en BOBNEO).

8) astroturismo; aviturismo; espeleoturismo y micoturismo. Hemos acordado el criterio de la motivación para la selección de nuestro corpus y lo hemos vinculado a los distintos atractores del destino, pero, como ya indicamos, los atractores se entrecruzan en las distintas motivaciones y la clasificación que hemos presentado es relativa. Así, entre los atractores naturales, hemos encuadrado, por ejemplo, aviturismo, pero cuando se oferta un espacio natural como, por ejemplo, el Parque Nacional de Doñana, que fue declarado en 1980 Reserva de la Biosfera, ¿estamos ante un atractor natural o cultural? Si visitamos una web institucional, como el Portal oficial de turismo de España $^{38}$, nos encontramos con que se nos presentan distintos servicios turísticos desarrollados, principalmente, por empresas de ecoturismo. La mayoría de estas empresas ofertan actividades que se inscriben en el turismo activo, por tanto, un turismo de naturaleza, pero otras ofrecen actividades didácticas y de educación ambiental, algunas de ellas ligadas a la observación de aves. Por tanto, cabe la posibilidad de desarrollar un tipo de turismo cultural de tipo educativo al practicar el aviturismo.

9) turismo de negocios, turismo corporativo y turismo de congresos. El turismo corporativo y el turismo de congresos serían subtipos del turismo de negocios, siendo el corporativo concerniente a empresas y el de congresos a asociaciones, instituciones, colegios profesionales, etc. (Aguilar 2008: 112). No obstante, como suele suceder con los hiperónimos, se usa con frecuencia turismo de negocios en lugar de turismo corporativo, lo que puede llevar a interpretarlos como sinónimos. Linguaturismo (2014) establece correspondencia entre el español turismo de negocios y el italiano turismo d'affari, pero también indica este último término para el préstamo del inglés business travel, refiriéndolo exclusivamente a eventos corporativos y para viaje de negocios, se indica para italiano viaggio d'affari.

10) narcoturismo; turismo cannábico; turismo de trasplante; turismo electoral; turismo médico; turismo sanitario; turismo sexual y turismo suicida. Situamos todas estas modalidades entre las que corresponden a atractores artificiales porque, como adelantamos, hay una motivación "comercial". El narcoturismo y el turismo cannábico están motivados por la adquisición y consumo de drogas en los países o regiones en los que su venta está legalizada o, en todo caso, donde son fácilmente accesibles. No obstante, narcoturismo presenta en su uso una inestabilidad semántica, pues normalmente se usa con el sentido con el que aparece definido en el diccionario electrónico NEOMA (2016): 'turismo que tiene como finalidad el consumo de drogas', pero también se documenta referido a la realización de rutas para visitar lugares donde operaron famosos capos del narcotráfico, como Escobar ${ }^{39}$. Por otro lado, el turismo sexual y el turismo suicida tienen que ver

38 El enlace al portal es este: <https://www.spain.info/es/que-quieres/naturaleza/espacios-naturales/parque nacional_de_donana.html>

39 Leemos en una noticia distribuida por Europa Press con fecha 9 de marzo de 2018: "El 'narcoturismo' parece haber despegado en Medellín (Colombia) donde multitud de turistas se desplazan cada vez con mayor frecuencia para realizar alguna de las rutas turísticas relacionadas con el narcotraficante Pablo Escobar (1949-1993) que se ofrecen 
con la permisividad legal, respectivamente, para la transacción comercial del sexo y para la práctica de la eutanasia. Como vimos, el turismo médico o sanitario puede conceptualizarse como un subtipo del turismo de salud, pero puede emplearse focalizando en la viabilidad o el menor coste de determinados tratamientos médicos en el destino y por ello también se puede conceptualizar como una modalidad en la que se hace prominente un atractor artificial; en este último caso, el turismo de trasplante representaría un subtipo de este denominado turismo médico. Por último, el turismo electoral está motivado, según Nieto y Espíndola (2017: 229), por promesas y, en ocasiones, amenazas, de índole económico o político que llevan al usuario a cambiar de domicilio para figurar en el padrón electoral en unas elecciones.

11) turismo de sol y playa. Como vimos, esta modalidad se muestra como la menos valorada para las próximas décadas, pero el hecho es que en la actualidad el litoral se elige como destino en una proporción de más de uno por cada dos viajes (Valls 2013: 385-386). En un trabajo sobre el papel de la imagen del turismo de sol y playa, Bigné, Sánchez y Currás apuestan por la necesaria transformación del modelo tradicional de sol y playa en un modelo con una oferta complementaria diversificada y en el que se tiene una mejora de los servicios turísticos (2007: 58). Para ello, identifican cinco dimensiones en la imagen del destino de sol y playa (2007: 67): a) Infraestructuras; b) Oferta turística básica; 3) Playas; 4) Ambiente; y 5) Atractivos turísticos complementarios. Entre estos últimos incluyen: atracciones históricas y culturales; entornos naturales bellos y oferta de ocio y entretenimiento atractiva. Realizan un experimento con personas mayores de edad de la Comunidad Valenciana, interrogándoles sobre su último destino de sol y playa; por tanto, se evalúa este destino posteriormente a su compra. Los resultados muestran que el mayor peso en la satisfacción de los turistas es el de los atractivos turísticos complementarios, si bien con poca diferencia con respecto a los otros factores, mientras que las infraestructuras tienen un papel marginal. No obstante, su intención de regresar venía marcada por las playas (su calidad, acondicionamiento y limpieza), y después, con muy poca diferencia, por los atractivos turísticos complementarios de nuevo. Como los autores reconocen, el estudio tendría que completarse atendiendo al componente afectivo de la imagen, pero estos datos sobre la componente cognitiva son relevantes en el dominio de la gestión y el marketing turísticos.

En conclusión, aunque los términos del turismo que representan una motivación son aparentemente transparentes -lo que tiene que ver con su constitución formal-, hemos comprobado que se presentan denominaciones que pueden coincidir parcialmente en su contenido, encontrándonos en algunos casos usos sinónimos que no lo son de forma absoluta, además de denominaciones que están en relación de inclusión semántica con distintos términos genéricos, dependiendo de la faceta conceptual que se haga prominente en el contexto de uso.

Por la concurrencia de distintos factores socioeconómicos y socioculturales, se ha pasado de un turismo de masas a un turismo individualizado y, por ende, mucho más específico, lo que conduce a una reestructuración y ampliación de modalidades por motivación que se plasma en el nuevo léxico. La elaboración de denominaciones para turistas y alojamientos vinculados a estas

en la ciudad" <https://www.europapress.es/turismo/mundo/noticia-narcoturismo-despega-colombia-mano-pabloescobar-20180309130421.html> 
modalidades es muestra de su afianzamiento y de la tendencia a elegir productos por motivación en el panorama de un turismo diversificado.

\section{Conclusiones}

La extraordinaria reestructuración del turismo como actividad socioeconómica y sociocultural ha generado la creación de términos para denominar modalidades por motivación en los que se identifican atractores, pero que se definen, no únicamente con relación a atributos, sino por contraposición al turismo convencional. Hemos analizado 39 de estos términos, localizados entre los 198 neologismos del turismo que hemos extraído del BOBNEO, y los hemos puesto en correspondencia con los distintos atractores del destino (naturales, culturales y artificiales).

Al realizar la discusión sobre los atributos destacados en los términos, hemos comprobado que su clasificación según los atractores que motivan la elección del destino es relativa, puesto que la motivación puede ser híbrida; por ejemplo, en el turismo educativo (atractor cultural) que se desarrolla en un entorno natural privilegiado (atractor natural) la elección está motivada tanto por valores ecológicos como por el aprendizaje. Esto se hace más evidente en modalidades como el turismo rural (atractor natural) o el etnoturismo (atractor cultural), donde la experiencia cultural y el entorno natural se muestran inseparables. Más aún, podríamos plantear la influencia de modelos culturales en modalidades vinculadas a atractores naturales; así, el turismo de salud y belleza (atractor) tiene un componente cultural, dado que, si bien balnearios y centros de talasoterapia están condicionados por los recursos naturales del lugar, lo cierto es que los hábitos saludables y el cuidado de la imagen forman parte del ideal de belleza de nuestra cultura.

Por otro lado, hemos abordado las relaciones semánticas entre términos y se ha justificado que se sitúen en la misma categoría de atractores naturales, por ejemplo, turismo de salud y turismo termal (en relación de hiperonimia-hiponimia), mientras que turismo médico se separa de turismo de salud (en relación de sinonimia parcial) y se coloca en la categoría de atractores artificiales. Ello tiene que ver con la conceptualización de salud y su redefinición en el sector para incluir atributos diversos. También hemos tratado los límites de conceptualización de lo cultural en el término turismo cultural, pues puede restringirse a lo histórico-artístico y monumental, o a eventos como festivales, o bien puede extenderse a cualquier aspecto antropológico del destino. En sentido extenso, turismo cultural sería hiperónimo de denominaciones altamente específicas, como turismo enológico, como también de otras en las que la motivación representada es más compleja, como etnoturismo, que se conceptualiza como tipo de turismo alternativo. Además, hemos dado cuenta de que hay modalidades, como el turismo sexual, que pueden relacionarse con el turismo de negocios por cuanto comparten una motivación "artificial" (no vinculada a recursos naturales ni culturales), por más que sean prácticas con fines muy diferentes. En definitiva, el análisis realizado ha permitido establecer la red conceptual de términos y mostrar su actualización de acuerdo a la faceta del atractor que fundamenta la motivación que se representa.

Finalmente, concluimos que la terminología de modalidades por motivación ha experimentado una transformación relevante en las primeras décadas del siglo XXI debido a la evolución del turismo de masas hacia un turismo experiencial y personalizado que, además, está en consonancia con el modelo de desarrollo sostenible que se defiende desde los últimos años del siglo XX. Los 
términos de modalidades analizados corresponden a la diversificación de motivaciones del potencial turista, que planifica el disfrute de su tiempo vacacional y de ocio buscando prácticas que lo involucren tanto cognitiva como emocionalmente. Los expertos en gestión turística proponen productos acordes con estas nuevas motivaciones y alejados de patrones tradicionales, en los que la expectativa sea una experiencia o vivencia, y no una repetición de fórmulas, por más que esto sea de algún modo inevitable por cuanto se trata de productos procesados. En definitiva, al analizar en los términos la representación de atributos específicos que intervienen en la construcción de la imagen del destino turístico, accedemos a las diversas motivaciones para elegir un determinado producto turístico.

\section{Referencias bibliográficas}

Aguilar Sánchez, J. (2008). Marketing en el turismo de negocio: análisis de evolución de la demanda en el turismo de reuniones. Revista de Comunicación de la SEECI, 17, 97-125.

Aires, G.; \& Nicolau, K. C. (2010). Marketing turístico internacional. La marca Brasil. Estudios y perspectivas en turismo, 19, 2, 241-267.

Alonso Benito, L. E. (2009). Los nuevos patrones de consumo turístico y los estilos de vida: una aproximación sociocultural. In J. M. Rodríguez, \& M. M. Alonso (Eds.), Nuevas tendencias y retos en el Sector Turismo: un enfoque multidisciplinar (pp. 245-265). Madrid: Delta Publicaciones Universitarias.

Álvarez-Sousa, A. (1994). El ocio turístico en las sociedades industriales avanzadas. Barcelona: Bosch Casa Editorial.

Arias, F. J.; Caraballo, A. M.; \& Matos, R. E. (2012). El turismo de salud: Conceptualización, historia, desarrollo y estado actual del mercado global. Clío América, 6, 11, 72-98.

AUREN (2013). Turismo de salud en España. Madrid: Fundación EOI. <https://turismo.gob.es/es-ES/Servicios/Documents/turismo_salud_espana.pdf>

Bautista Moya, A.; Fernández Ramón, F.; \& Santandreu Mascarell, C. (2016). El turismo de salud: situación actual y retos de futuro en la Comunitat Valenciana (España). Turismo \& Sociedade, 9, 2, 1-25.

Bigné, E.; Sánchez, I.; \& Currás, R. (2007). El papel de la imagen del destino en la valoración y comportamiento postcompra del turista de sol y playa. Papers de Turisme, 42, 57-73.

Cabré, M. T. (2008). El principio de poliedricidad: la articulación de lo discursivo, lo cognitivo y lo lingüístico en Terminología (I). Ibérica, 16, 9-36.

Calvi, M. V. (2001). El léxico del turismo. In Á. M. Felices Lago (Coord.), El ELE para contextos profesionales. Cultura e intercultura en la enseñanza del español a extranjeros. Barcelona: Universitat de Barcelona.

. (2016). Léxico de especialidad y lengua del turismo. In A. L. Duffé (Ed.), Estudios sobre el léxico (pp. 187-214). Bern: Peter Lang.

Calvi, M. V.; \& Mapelli, G. (2011). Introducción. In M. V. Calvi, \& G. Mapelli (Eds), La lengua del turismo. Géneros discursivos y terminología (pp. 9-16). Bern: Peter Lang.

Carcavilla, L.; Belmonte, Á.; Durán, J. J.; \& Hilario, A. (2011). Geoturismo: concepto y perspectivas en España. Enseñanza de las Ciencias de la Tierra, 19, 1, 81-94.

Carpi, E. (2013). La neología léxica en el discurso del turismo: análisis de blogs profesionales del corpus Linguaturismo. In L. Chierichetti, \& G. Garofalo (Eds.), Discurso Profesional y Lingüística de Corpus, 
Perspectivas de Investigación (pp. 51-71). Bergamo: CELSB, CERLIS Series, 3. <https://aisberg.unibg.it/ retrieve/handle/10446/29361/146855/cerlis_3_full_1044629361.pdf>

Cebrián, F.; \& García, C. (2016). Uso y gestión del paisaje para la actividad turística en el medio rural: aproximación teórica y empírica en el sureste de Castilla-La Mancha (Albacete). Boletín de la Asociación de Geógrafos Españoles, 72, 381-407.

Chierichetti, L.; Garofalo, G.; \& Mapelli, G. (2019). Hacia una visión holística del discurso turístico. Círculo de Lingüística Aplicada a la Comunicación, 78, 3-16.

[DLE]: Diccionario de la lengua española. <https://dle.rae.es/>

Estornell Pons, M. (2016). Del turismo ecológico al ecoturismo: análisis de las unidades léxicas de un turismo emergente. Círculo de Lingüística Aplicada a la Comunicación, 67, 110-135.

Falcón, J. P. (2017). La identidad, imagen y reputación de un destino turístico urbano a través de la gestión de la comunicación online: el caso de la ciudad de Buenos Aires. Tesis Doctoral. Universidade da Coruña, España. <https:// ruc.udc.es/dspace/bitstream/handle/2183/19545/Falcon_JuanPablo_TD_2017.pdf?sequence=3\&isAllowed=y>

Fayos-Solà, E. (2004). Política turística en la era de la globalización. Mediterráneo económico, 5, 215-232.

Fayos-Solà, E.; Muñoz, A. I.; \& Fuentes, L. (2011). El modelo FAS: orígenes, desarrollo y aplicación en destinos turísticos. Estudios turísticos, 188, 27-62.

Gallarza, M. G.; Gil, I.; \& Calderón, H. (2002). Destination Image. Towards a Conceptual Framework. Annals of Tourism Research, 29, 1, 56-78.

Gil Álvarez, E. (2004). Vacaciones en la naturaleza: reflexiones sobre el origen, teoría y práctica del ecoturismo. Polígonos. Revista de Geografía, 14, 17-52.

Guerrero Ramos, G. (2016). Nuevas orientaciones en la percepción de los neologismos: neologismos de emisor y neologismos de receptor o neologismos de receptor. In J. García Palacios, G. De Sterck, D. Linder, N. Maroto, M. Sánchez Ibáñez, \& J. Torres del Rey (Eds.), La neología en las lenguas románicas: recursos, estrategias y nuevas orientaciones (pp. 57-68). Frankfurt am Main: Peter Lang.

Guerrero Velasco, A.; Campón Cerro, A. M.; \& Hernández Mogollón, J. M. (2012). Aproximación al concepto de agroturismo a través del análisis de la legislación española en materia de agroturismo. In Turismo y sostenibilidad: V Jornadas de investigación en turismo (pp. 33-54). Sevilla: Facultad de Turismo y Finanzas.

Hidalgo, M. C.; Sicilia, M.; \& Ruiz de Maya, S. (2012). La imagen de destino y el contenido generado por otros usuarios: el caso del turismo rural. In A. Guevara, A. Aguayo, J. L. Caro, \& A. Cerezo (Coords.), Turitec2012: IX Congreso Nacional Turismo y Tecnologías de la Información y las Comunicaciones (pp. 364-379). Málaga: Universidad de Málaga.

Huete, R.; Mantecón, A.; \& Mazón, T. (2008). ¿De qué hablamos cuando hablamos de turismo residencial? Cuadernos de Turismo, 22, 101-121.

ITREM. (2018). La demanda turística en la Región de Murcia. Turismo de salud y belleza. Primavera 2018. In Turismo en la Región de Murcia. Estudios y Estadísticas. Estudios de productos. Turismo de Salud. Primavera 2018. Murcia: Consejería de Turismo y Cultura.

[Linguaturismo]: Glosario español-italiano sobre la gestión del turismo. (2014). Anejo ${ }^{\circ} 6$ de Normas. Revista de Estudios Lingüisticos Hispánicos <https://www.uv.es/normas/2014/anejos/Libro_glosario_2014.pdf>

Loscertales, B. (1999). El turismo rural como forma de desarrollo sostenible. El caso de Aragón. Geographicalia, 37, 123-138.

Moral, S.; Cañero, P.; \& Orgaz, F. (2013). El turismo de aventura: concepto, evolución, características y mercado meta. El caso de Andalucía. In J. L. Jiménez Caballero (Coord.), Turismo e innovación: IV Jornadas de investigación en turismo (pp. 327-343). Sevilla: Universidad de Sevilla. 
Nieto, S.; \& Espíndola, L. (2017). La persecución y sanción de los delitos electorales en ambientes de violencia y el Estado de derecho. El caso mexicano 2015-2016. In S. Romero (Ed.), Democracia, elecciones y violencia en América Latina (pp. 221-244). Tegucigalpa: Instituto Universitario en Democracia, Paz y Seguridad.

[NTLLE]: Nuevo Tesoro Lexicográfico de la Lengua Española. <http://ntlle.rae.es/ntlle/SrvltGUILoginNtlle>

Osorio Acosta, E. (2005). Gestión competitiva en los destinos turísticos de interior. Tesis Doctoral. Universidad Politécnica de Valencia, España. <https://riunet.upv.es/bitstream/handle/10251/1893/tesisUPV2351.pdf>

Prieto Gutiérrez, J. J. (2015). Turismo cultural: el caso español. International Journal of Scientific Management and Tourism, 2, 95-114.

Rivera Mateos, M. (2010). Turismo activo en la naturaleza y espacios de ocio en Andalucía: aspectos territoriales, políticas públicas y estrategias de planificación. Tesis Doctoral. Universidad de Córdoba, España. $<$ http://hdl.handle.net/10396/14269>

Salazar, N. B. (2006). Antropología del turismo en países en desarrollo: análisis crítico de las culturas, poderes e identidades generados por el turismo. Tabula Rasa, 5, 99-128.

Sánchez Manzanares, C. (2020). "Neologismos del turismo e ideología: la sostenibilidad y la interculturalidad en la elaboración terminológica". Tonos digital, 39, 1-21.

Sánchez Manzanares, C.; Azorín Fernández, D.; \& Santamaría Pérez, I. (2016). NEOMA. Diccionario de neologismos del español actual. Murcia: Editum. <https://www.um.es/neologismos/index.php/>

Sanmartín Sáez, J. (2016a): “Sobre neología y contextos de uso: Análisis pragmalingüístico de lo ecológico y de lo sostenible en normativas y páginas web de promoción turística. Ibérica: Revista de la Asociación Europea de Lenguas para Fines Especificos, 31, 175-198.

- (2016b). Variación léxica geolectal, legislación sectorial y estandarización: las denominaciones de los establecimientos de alojamiento turístico en el español de América. ELUA, 30, 257-274.

. (2019). Análisis del discurso, ideología y neologismos: 'turismofobia, 'turistización' y 'turistificación’ en el punto de mira. Círculo De Lingüística Aplicada a La Comunicación, 78, 63-90.

Santana Talavera, A. (2003). Turismo cultural, culturas turísticas. Horizontes Antropológicos, 20, 31-57.

Seco, M., Andrés, O., \& Ramos, G. (1999). Diccionario del español actual. Madrid: Aguilar.

Talón, P.; \& Figueroa, C. (2009). Los nuevos productos turísticos. In J. M. Rodríguez, \& M. M. Alonso (Eds.), Nuevas tendencias y retos en el Sector Turismo: un enfoque multidisciplinar (pp. 147-175). Madrid: Delta Publicaciones Universitarias.

Valls Giménez, J. F. (2013). Planificación estratégica de destinos turísticos. Aspectos diferenciales por tipologías. In J. I. Pulido, \& Y. López (Eds.), Gestión estratégica sostenible de destinos turísticos (pp. 375-424). Sevilla: Universidad Internacional de Andalucía.

Vargas Hernández, J. G. (2013). Desarrollo regional y sustentabilidad: turismo cultural en la región sur de Jalisco. Revista Dimensión Empresarial, 11, 2, 36-50.

Varo Varo, C. (2017). Similitud y contraste en el procesamiento léxico: aproximación teórico-práctica. Anuario de Letras. Lingüística y Filología, V, 2, 183-211.

[VOXUSO]: VOX. Diccionario de uso del español de América y España. (2003). Barcelona: Spes Editorial. Yus Ramos, F. (2010). Ciberpragmática 2.0. Nuevos usos del lenguaje en Internet. Barcelona: Ariel. 
